\title{
Anti Hyperglycemic, Anti Oxidant, Anti Hyperlipidemic \& Nephroprotective Effect of Stevioside in Diabetic Rats
}

\author{
Research Article
}

\author{
Ambily Scaria $^{*}$, Jagadhish V Kamath ${ }^{2}$, Manodeep Chakraborty ${ }^{3}$
}

\begin{abstract}
1. Department of Pharmacology, St. Johns College of Pharmaceutical Sciences and Research, Kattappana
2. Principal and HOD, Shree Devi College of Pharmacy, Mangalore

3. Department of Pharmacology, Yenepoya Pharmacy College and Research Centre, Mangalore
\end{abstract}

\begin{abstract}
Objective: The present study aimed to evaluate in vivo the antihyperglycemic, anti oxidant,antihyperlipidemic and nephroprotective effects of Stevioside against Alloxan induced diabetic nephropathy in rats. Materials and Methods: In this model diabetes was induced using Alloxan (125 mg/ $\mathrm{kg}$, i.p) and the prophylactic treatment was started 48 hours after Alloxan injection for 28 days. The protective effect of the treatment with standard (Glibenclamide $0.5 \mathrm{mg} / \mathrm{kg}$, p.o) and Stevioside $(250 \mathrm{mg}$ ) kg. p.o) were analyzed by estimating the serum levels of glucose, urea, creatinine, albumin, total protein, total cholesterol (TCH), triglycerides (TG), high density lipoproteins (HDL) and antioxidants like SOD, catalase and lipid peroxidation. Key Findings: This study demonstrates that Stevioside improved hyperglycemia and maintained antioxidant status and reduced total cholesterol, TG, urea, creatinine and albumin and lipid peroxidation levels when compared to toxic control. The protective effect of Stevioside against Alloxan induced diabetic nephropathy in rats was also supported by histopathologic findings. The results of the present study are encouraging for its potential use to delay the onset and progression of diabetic renal complications. However, the translation of therapeutic efficacy in humans requires further studies.
\end{abstract}

Keywords: Stevioside, Alloxan, nephropathy, antioxidants, histopathology.

\section{Introduction}

Diabetes mellitus is a metabolic disorder characterized by chronic hyperglycemia with disturbances of carbohydrate, fat and protein metabolism due to defects in insulin secretion, insulin action, or both. The chronic hyperglycemia of diabetes is associated with long-term damage, dysfunction and failure of various organs, especially the eyes; kidneys, nerves, heart, and blood vessels referred to us retinopathy, nephropathy, neuropathy and cardiomyopathy respectively (1).

Diabetic Nephropathy is a progressive kidney disease caused by damage to the capillaries in the kidney's glomeruli due to longstanding diabetes mellitus. Renal disease in diabetes is found to be associated with abnormalities of vasodilation and generates reactive oxygen species mediated by endothelial derived nitric oxide (NO) (2).

Experimental evidence has supported that reactive oxygen species play a role in both pathogenesis and numerous pathophysiological mechanisms that trigger diabetic complications. The possible biochemical mechanisms include activation of the

*Corresponding Author:

Ambily Scaria

Department of Pharmacology, St. Johns College of

Pharmaceutical Sciences and Research

Kattappana south PO. - 685515, Kerala, India

Email: ambilyscaria.ms@gmail.com polyol pathway, activation of protein kinase C (PKC), formation of glycation end products and increased oxygen stress (3).

The pathogenesis of diabetes mellitus are managed by insulin and oral administration of hypoglycemic drugs such as sulfonylureas and biguanides (4).Unfortunately, apart from having a number of side effects, none of the oral synthetic hypoglycemic agents have been successful in diabetes management and controlling long-term micro vascular and macro vascular complications (5).

Prior to the discovery of insulin dietary measures and the traditional medicines derived from plants were the major forms of treatment for diabetes and its complications. Among the anti-diabetic plants, Stevia (Stevia rebaudiana Bertoni) that belongs to the Asteraceae family is one of the most efficacious plants. The basic building block that gives a sweet taste to the leaves of the stevia is glycoside (Stevioside) (6).A number of studies have suggested that, beside sweetness, stevioside may also offer therapeutic benefits, as they have anti-hyperglycemic, antihypertensive, anti-inflammatory and anti-cancer effects (7).

Extract from as Stevia rebaudiana has long been used for the treatment of diabetes. It also exhibits a high degree of antioxidant activity which has been attributed to the scavenging of free radical electrons and superoxides. They also do not induce a glycemic response when ingested, making them attractive as 
natural sweeteners to diabetics and others on carbohydrate-controlled diets (8).

The reported mechanism of action for steviol glycosides involves the enhanced secretion of insulin from $\beta$ cell of pancreas and insulin sensitivity of peripheral tissues, promoting glucose uptake $(9,10)$. Stevioside also inhibits glucose production by inhibiting glucagon secretion from $\alpha$ cell of pancreas, which affects gluconeogenesis and glycogenolysis (11).

Previous studies reported anti-hyperglycemic activity of both aqueous extract of Stevia rebaudiana and the isolated Stevioside $(10,12,13)$. But till now there is no reported study on the use of Stevioside, the active phytoconstituent against diabetes related complications. Hence the present study was designed to evaluate the effect of Stevioside against alloxan induced diabetic nephropathy in rats.

\section{Materials and Methods Experimental animals}

Rats of either sex weighing 175-250 g were housed in standard polypropylene cages and maintained under controlled room temperature $\left(25^{\circ} \pm 5^{\circ} \mathrm{C}\right)$ and humidity $(55 \pm 5 \%)$ in a well-ventilated animal house under 12:12 $\mathrm{h}$ light and dark cycle. All the rats were provided with commercially available standard pellet diet, water ad libitum. Prior to each study, the animals were made to fast for $12-14 \mathrm{~h}$ but had free access to water. The guidelines of committee for the purpose of control and supervision of experiments on animals (CPSCEA), Govt. of India were followed and prior permission was sought from the institutional animal ethics committee for conducting the study.

\section{Procurement of Stevioside and its dose selection}

Pure Stevioside was procured from Yucca Enterprises, Mumbai, India in the month of June, 2013.Stevioside solution was suspended using water and administered orally to the animals by gastric intubation using a force feeding needle. Based on an earlier literature review therapeutic dose of Stevioside in rats was found to be $250 \mathrm{mg} / \mathrm{kg}$ and the same dose was selected for the present study (14).

\section{Experimental Model: Alloxan induced diabetic nephropathy $(15,16)$}

Diabetes was induced by intra peritoneal injection of a freshly prepared aqueous solution of 5\% alloxan monohydrate $(125 \mathrm{mg} / \mathrm{kg}$ body weight $)$ in normal Saline. After $24 \mathrm{~h}$ fasting, blood was withdrawn from the tail vein for glucose analysis. $48 \mathrm{~h}$ after alloxan administration, rats with fasting glucose ranging from 210-220 mg/dl showing clear signs of polyuria, polyphagia and polydipsia were considered diabetic. Animals with fasting blood glucose less than $200 \mathrm{mg} / \mathrm{dl}$ was not used for experimentation.

\section{Experimental design}

Overnight fasted rats were divided into four groups containing 6 animals in each group. Treatment with Stevioside was started $48 \mathrm{~h}$ after alloxan injection and continued for 4 weeks.
- Group I - Normal Control

- Group II - Toxic Control (Alloxan 125mg/kg, i.p.)

- Group III - Standard (Glibenclamide $0.5 \mathrm{mg} / \mathrm{kg}$ P.O.)

- Group IV - Stevioside (250 mg/kg p.o.)

\subsection{Biochemical parameters}

Blood glucose was measured with Blood glucose kit (Robonik India Pvt Ltd, Mumbai) at weekly intervals on day 7, 14, 21 and 28 after daily administration of stevioside orally. 24 hours after the last treatment blood was collected by retro orbital puncture and serum was separated by centrifugation. Then after sacrificing the animals kidney samples were collected. Kidney samples collected were used for histopathological analysis and preparation of Kidney tissue homogenate. Both serum and Kidney tissue homogenate was subjected for different biochemical parameters like Blood urea nitrogen, Creatinine, Total protein, Total cholesterol, Triglycerides, HDLcholesterol in serum and SOD, catalase and lipid peroxidation in Kidney tissue homogenate (17-26).

\section{Preparation of Kidney Tissue Homogenate (27)}

Samples of kidneys $\left(100 \mathrm{mg} \mathrm{mL}^{-1}\right.$ buffer $)$ were homogenized using a mortar and pestle in $50 \mathrm{mM}$ phosphate buffer $(\mathrm{pH} 7.0)$, and then centrifuged at 10,000 RPM for $15 \mathrm{~min}$; the supernatant thus obtained was used for biochemical analysis.

\section{Statistical Analysis}

Results were expressed as mean \pm SEM. Statistical significance was assessed using One-way analysis of variance (ANOVA) followed by TukeyKarmer multiple comparison tests by Graphpad Instat 3.06 software. $\mathrm{P} \leq 0.05$ was considered significant.

\section{Results}

\section{Anti-diabetic activity}

Single dose alloxan monohydrate $(125 \mathrm{mg} / \mathrm{kg})$ significantly $(\mathrm{P}<0.01)$ increases the blood glucose as shown in Table 1. After the daily oral administration with Stevioside (250 mg/kg, p.o.), for 28 days, extremely significant $(\mathrm{P}<0.001)$ decrease in the blood glucose levels was observed in the diabetic rats.

\section{Effect of Stevioside on antioxidant levels in kidney tissue homogenate (KTH)}

The effect of Stevioside on antioxidant levels in $\mathrm{KTH}$ of Alloxan induced diabetic rats was shown in Table 2. In this experimental model, toxic control revealed an extremely significant $(\mathrm{P}<0.001)$ decrease of SOD and catalase activity and an extremely significant $(\mathrm{P}<0.001)$ increase in lipid peroxidation in KTH when compared to normal control. The prophylactic treated groups like standard and stevioside $(250 \mathrm{mg} / \mathrm{kg})$ demonstrated an extremely significant $(\mathrm{P}<0.001)$ increase of SOD and catalase activity when compared with toxic control while an extremely significant $(\mathrm{P}<0.001)$ and moderately significant $(\mathrm{P}<0.01)$ decrease in lipid peroxidation is shown by the standard and Stevioside. 


\section{Effect on Lipoproteins}

In toxic control group, there was an extremely significant $(\mathrm{P}<0.001)$ increase of serum total cholesterol $\&$ triglycerides, and an extremely significant $(\mathrm{P}<0.001)$ decrease of HDL cholesterol when compared to that of normal controls. The standard drug as well as Stevioside (250 $\mathrm{mg} / \mathrm{kg}$ ) used in the experimental study showed an extremely significant decrease $(\mathrm{P}<0.001)$ in the levels of cholesterol and triglycerides whereas an extremely significant increase in HDL cholesterol was observed (Table 3).

\section{Effect on Kidney function markers}

Kidney function markers like creatinine, urea and albumin were elevated in the alloxan induced diabetic rats when compared with the normal rats while total protein level is decreased when compared with the normal rats. Stevioside reduced the levels of creatinine, urea and albumin and increased the levels of total protein when compared to toxic control (Table 4).

\section{Histology of Kidney (Figure 1)}

Histology of kidney in normal rats showed the normal structure (A). In diabetic rats, mild thickening of the basement membrane of the arterioles of glomeruli along with severe tissue degranulation were observed. No other significant changes were seen (B). These changes were improved towards normal on treatment with standard (C) and Stevioside (D).
Figure1. Histopathology of rat kidney tissue in Alloxan induced diabetic nephropathy
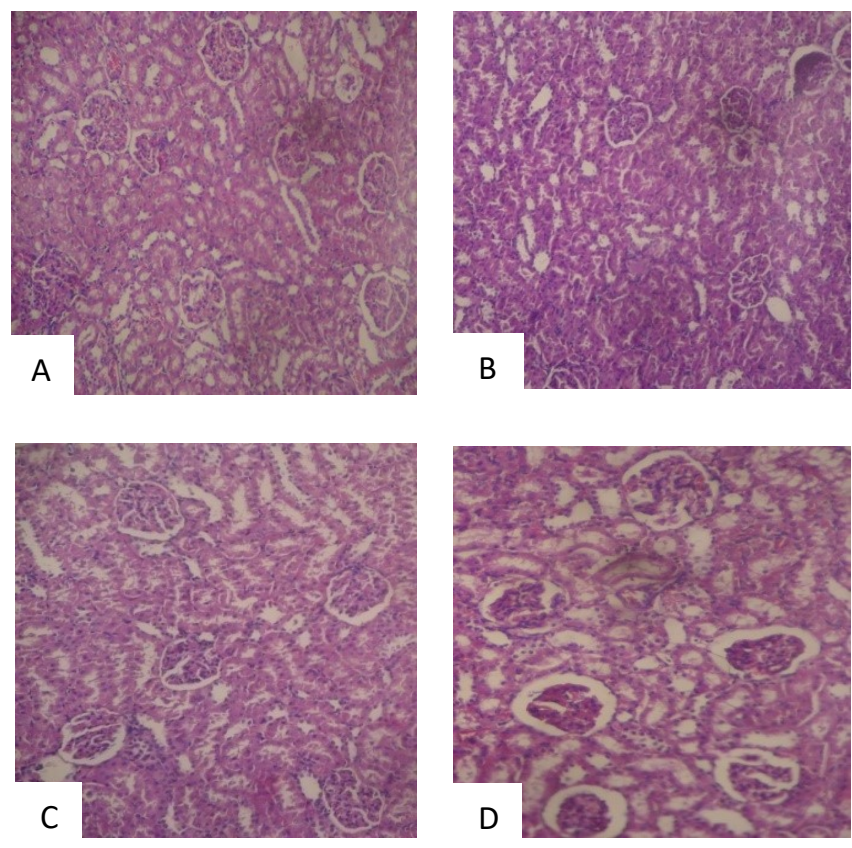

Effect of Standard and Stevioside $(250 \mathrm{mg} / \mathrm{kg})$ on rat kidney in alloxan induced diabetic nephropathy :A:Normal rats, B: Diabetic rats, C: Standard Treated, D: Stevioside Treated.

Tables and Figures

Table 1: Effect of Stevioside on the serum blood glucose levels

\begin{tabular}{|c|c|c|c|c|}
\hline \multirow{2}{*}{$\begin{array}{c}\text { Groups/ } \\
\text { Treatment }\end{array}$} & & \multicolumn{3}{|c|}{ Blood glucose level } \\
\hline & Day 7 & $\overline{\text { Day } 14}$ & Day 21 & Day 28 \\
\hline Normal control & $106.28 \pm 4.50$ & $105.34 \pm 3.80$ & $98.70 \pm 5.20$ & $97.35 \pm 9.33$ \\
\hline Toxic control & $249.53 \pm 2.47^{\text {twat }}$ & 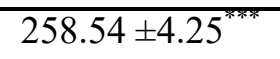 & $265.46 \pm 4.27^{* *}$ & $281.33 \pm 4.80^{* * 7 *}$ \\
\hline Standard & $230.24 \pm 2.38^{* \pi \cdots}$ & $215.23 \pm 3.52^{\cdots \cdots \# \#}$ & $132.31 \pm 2.34 *$ \#\#\# & $122.00 \pm 3.05^{\text {\#\#\# }}$ \\
\hline Stevioside & $235.21 \pm 2.24$ & $230.20 \pm 2.25^{* \cdots n \# f}$ & $184.20 \pm 2.25^{* n \# \#}$ & 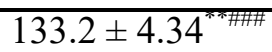 \\
\hline
\end{tabular}

All values are mean \pm SEM, $n=9,{ }^{*} \mathrm{p}<0.05,{ }^{* *} \mathrm{p}<0.01$ when compared to normal control, ${ }^{\# \#} \mathrm{p}<0.01,{ }^{\# \#} \mathrm{p}<0.001$ compared to toxic control.

Table 2: Effect of Stevioside on antioxidant levels in KTH

\begin{tabular}{|c|c|c|c|}
\hline $\begin{array}{c}\text { Groups/ } \\
\text { Treatment }\end{array}$ & $\begin{array}{c}\text { SOD } \\
\text { (unit/mg protein) }\end{array}$ & $\begin{array}{c}\text { Catalase } \\
\text { (unit/mg protein) }\end{array}$ & $\begin{array}{l}\text { Lipid peroxidation } \\
\text { (unit/mg protein) }\end{array}$ \\
\hline Normal control & $80.73 \pm 2.65$ & $0.68 \pm 0.01$ & $1.76 \pm 0.11$ \\
\hline Toxic control & $11.71 \pm 1.11^{\pi}$ & $0.17 \pm 0.01$ & $4.59 \pm 0.12^{\pi / 2}$ \\
\hline Standard & $59.47 \pm 0.67$ & $0.55 \pm 0.02$ & $2.28 \pm 0.11^{\text {N\#\#\# }}$ \\
\hline Stevioside & $50.66 \pm 0.67^{*}$ & $0.47 \pm 0.008^{m}$ & $3.13 \pm 0.04$ \\
\hline
\end{tabular}

All values are mean $\pm \mathrm{SEM}, \mathrm{n}=9,{ }^{*} \mathrm{p}<0.05,{ }^{* *} \mathrm{p}<0.01,{ }^{* * *} \mathrm{p}<0.001$ when compared to normal control, ${ }^{\# \#} \mathrm{p}<0.01,{ }^{\# \#} \mathrm{p}<$ 0.001 compared to toxic control. 
Table 3: Effect of Stevioside on Lipoproteins (mg/dL)

\begin{tabular}{|c|c|c|c|}
\hline Groups/ Treatment & Serum HDL-C & Serum TC & Serum TG \\
\hline Normal control & $236.59 \pm 3.63$ & $146.60 \pm 6.90$ & $37.83 \pm 3.76$ \\
\hline Toxic control & $108.03 \pm 1.63^{m}$ & $254.46 \pm 8.20^{* \ldots}$ & $96.53 \pm 0.94^{\cdots}$ \\
\hline Standard & $224.40 \pm 5.14^{\# \#}$ & $158.13 \pm 3.18^{\# \# \#}$ & $49.35 \pm 7.25^{\# \# \#}$ \\
\hline Stevioside & $236.80 \pm 7.29^{\# \#}$ & $173.03 \pm 3.72^{\# \# \#}$ & $46.47 \pm 4.44^{\# \#}$ \\
\hline
\end{tabular}

All values are mean \pm SEM, $n=9, \stackrel{*}{p}<0.05$ and ${ }^{* * *} \mathrm{p}<0.001$ when compared to normal control, ${ }^{\# \# \#} \mathrm{p}<0.001$ compared to toxic control.

Table 4: Effect of Stevioside on Kidney function markers

\begin{tabular}{|c|c|c|c|c|}
\hline $\begin{array}{c}\text { Groups/ } \\
\text { Treatment }\end{array}$ & $\begin{array}{c}\text { Serum Urea } \\
(\mathrm{mg} / \mathrm{dL})\end{array}$ & $\begin{array}{c}\text { Serum Creatinine } \\
(\mathrm{mg} / \mathrm{dL})\end{array}$ & $\begin{array}{c}\text { Serum Albumin } \\
(\mathrm{mg} / \mathrm{dL})\end{array}$ & $\begin{array}{l}\text { Total protein } \\
(\mathrm{mg} / \mathrm{dL})\end{array}$ \\
\hline Normal control & $19.45 \pm 0.53$ & $1.23 \pm 0.06$ & $2.24 \pm 0.05$ & $78.11 \pm 1.41$ \\
\hline Toxic control & $44.72 \pm 2.34$ & $4.84 \pm 0.11$ & $5.26 \pm 0.24$ & $50.60 \pm 0.97$ \\
\hline Standard & 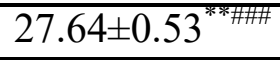 & $1.63 \pm 0.05^{*}$ & $3.24 \pm 0.05$ & 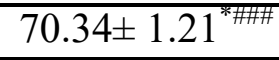 \\
\hline Stevioside & 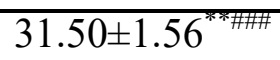 & 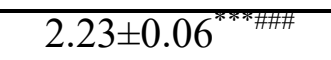 & $3.55 \pm 0.05^{* * \pi \ldots \# \#}$ & 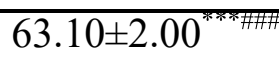 \\
\hline
\end{tabular}

All values are mean $\pm \mathrm{SEM}, \mathrm{n}=9,{ }^{*} \mathrm{p}<0.05,{ }^{* *} \mathrm{p}<0.01$ and $^{* * *} \mathrm{p}<0.001$ when compared to normal control ${ }^{\# \# \#} \mathrm{p}<0.001$ compared to toxic control

\section{Discussion}

Alloxan has been used to induce experimental diabetes due to the selective destruction of the insulinproducing pancreatic beta-islets. Alloxan induces a multiphasic blood glucose response when injected into an experimental animal, which is accompanied by a corresponding decrease in the plasma insulin concentration followed by sequential ultra-structural beta cell changes ultimately leading to necrotic cell death (28).

Convincing evidence has established the role of free radicals and oxidative stress in the pathogenesis and development of Diabetic nephropathy (29). Antioxidants like superoxide dismutase, catalase and the non-enzymatic scavengers of hydroxyl radicals have been found to protect against alloxan toxicity. A decline in level of catalase and SOD in the kidney tissue homogenate is due to the excessive generation of ROS or by glycation of the enzyme which have been noted to occur in diabetes (30).

Diabetes produces disturbances of lipid profiles, especially an increased susceptibility to lipid peroxidation, which is a critical biomarker of free radical-mediated oxidative stress. Hypercholesterolemia and hypertriglyceridemia were also observed in diabetic group which was decreased significantly with Stevioside. The observed hypolipidemic effect may be due to decreased cholesterol and fatty acid synthesis. HDL cholesterol level was significantly increased by Stevioside treatment. Any combination with antioxidant properties might contribute to the partial or total alleviation of oxidative damage (31).

In the present study a decrease in antioxidant activity in diabetic rats is observed, which may probably be due to the depletion of antioxidants. Stevioside is able to provide nephroprotective activity by increasing the reduced levels of SOD, Catalase, HDL and total protein while reducing the elevated level of glucose, creatinine, albumin, urea, lipid peroxidation and lipid profile. The probable mechanism of this action may be by reducing the production of ROS, preventing lipid peroxidation, modulating anti-oxidant enzyme levels (e.g. glutathione peroxidase, glutathione reductase, glutathione-S-transferase, superoxide dismutase and catalase) and the ability to scavenge oxidants. Histopathological studies of kidney tissues were undertaken and it was found that Stevioside was non-toxic and regenerated the toxic effects produced by alloxan.

\section{Conclusion}

From our findings, we infer that Stevioside has ability to ameliorate oxidative stress in Alloxan induced diabetic nephropathy in rats as evidenced by improved glycemic and reduced lipid peroxidation along with improved antioxidant enzymatic status. Moreover, it reverses histologic changes to almost normal due to lipid peroxidation which supports the anti oxidant property possessed by Stevioside.

The reported results were exciting, but the exact mechanism for the protective activities of Stevioside in diabetic nephropathy is still not clear and further investigation is required to understand the clear pharmacological profile of the same and to interpret the findings in clinical application.

\section{Conflicts of interest}

None

\section{Acknowledgement}

Thanks are due to Dr. K Upadhyay, Nanthikur laboratory, Mangalore, for histopathological studies.

\section{Funding}

This research did not receive any specific grant from funding agencies in the public, commercial or notfor-profit sectors.

\section{References}

1. El-Demerdash FM, Yousef MI, Abou El, Naga NI. Biochemical study on the hypoglycemic effects of 
onion and garlic in alloxan-induced diabetic rats. Food ChemToxicol. 2005;43(1): 57-63.

2. Ashish B, Swapnil G. Hypoglycemic effect of polyherbal formulation in alloxan induced diabetic rats. Pharmacologyonline 2011;3: 764-73.

3. Alhassan AJ, Sule MS, Atiku MK, Wudil AM, Abubakar H, Mohammed SA. Effects of aqueous avocado pear (Persea americana) seed extract on alloxan induced diabetes rats. Greener J Med Sci 2012 Jan;2(1): 5- 11.

4. Gilman G, Goodman LS. The pharmacological basis of therapeutics. 5th ed. New York: Macmillan; 1985.

5. Momin A. Role of indigenous medicine in primary health care.In: Proceedings of First International seminar on Unani Medicine New Delhi, India: 1987. p. 54 .

6. Jeppesen PB, Gregersen S, Poulsen CR, Hermansen $\mathrm{K}$. Stevioside acts directly on pancreatic beta cells to secrete insulin: Actions independent of cyclic adenosine monophosphate and adenosine triphosphate-sensitivie $\mathrm{K}^{+}$-channel activity. Metabolism 2000;49(2): 208-14.

7. Boonkaewwan C, Ao M, Toskulkao C, Rao M C. Specific immunomodulatory and secretory activities of stevioside and steviol in intestinal cells. J Agric Food Chem 2008;56(10): 3777-84.

8. http://en.wikipedia.org/wiki/Steviolglycoside retrieved on 28/11/2012 at 2:30p.m.

9. Awney HA, Massoud MI, El-Maghrabi S. Long-term feeding effects of stevioside sweetener on some toxicological parameters of growing male rats.J Appl Toxicol 2011 Jul;31(5):431-8.

10. Kujur RS, Singh V, Ram M, Yadava HN, Singh KK, Kumari $S$ et al. Antidiabetic activity and phytochemical screening of crude extract of Stevia rebaudiana in alloxan- induced diabetic rats. Pharmacognosy Res. 2010;2(4): 258-63.

11. Varanuj C, Chatchai M. Stevioside and related compounds: Therapeutic benefits beyond sweetness. Pharmacol Ther.2009;121(1): 41-54.

12. Hossain MS, Alam MB 1, Asadujjaman M, M, Islam MM etal. Antihyperglycemic and Antihyperlipidemic effects of different fractions of Stevia rebaudiana leaves in alloxan induced diabetic rats. Int $\mathrm{J}$ Pharm Sci res 2011;2(7): 1722-9.

13. Jeppesen PB, Gregersen S, Alstrup KK, Hermansen K. Stevioside induces antihyperglycaemic, insulinotropic and glucagonostatic effects in vivo: studies in the diabetic Goto-Kakizaki (GK) rats. Phytomedicine. 2002;9(1): 9-14

14. Deepika S, Munish P, Ashok KT, Nirmal S etal. Anti -amnesic effect of stevioside in scopolamine-treated rats. Indian j pharmacol. 2010;42(3): 164-7.

15. Ahmed N. Alloxan diabetes-induced oxidative stress and impairment of oxidative defense system in rat brain; neuroprotective effects of Cichorium intybus. Int J Diabetes metab 2009;17:105-9.

16. Kumar PN, Annamalai AR, Thakur RS. Antinociceptive property of Emblica officinalis Gaertn(Amla) in high fat diet-fed/low dose streptozotocin induced diabetic neuropathy in rats.
Indian J Exp Biol. 2009;47(10):778.

17. Reddy C, Amulya V, Lakshmi CH, Reddy PK, Prathima D, Thirupathi A, Kumar PK et al. Effect of simvastatin in Gentamicin induced Nephrotoxicity in Albino Rats. Asian J Pharm Clin Res. 2011;5(1): 3640.

18. Dwivedi S, Agarwal MP. Anti-anginal and cardioprotective effect of Terminariaarjuna, an indigeneous drug in coronary artery disease. J Assoc Physicians India. 1994;42(4):287-9.

19. Bolli R, Patel BS, Jeroudi MO. Demonstration of free radical generation in stunned myocardium of intact dogs with the use of the spin trap alpha-phenyl Ntertiary butyl nitrogen. J Clin Invest.1988;82(2): 47685.

20. Moss DW, Henderson AR. Clinical enzymology, Text book of clinical chemistry. W.B Saunders Company 1999;3:617-712

21. Young DS. Effects of drugs on clinical lab. Tests, 4th ed. AACC Press, 1995.

22. Bueke I, Prufer D, Dahm M, Meyer J, Oelerl H, Darius H. Blocking of classical compliment pathway inhibits adhesion molecule expression and preserve ischemic myocardium from reperfusion injury. $\mathrm{J}$ Pharmacol Exp Ther. 1998;286: 429-38.

23. Johnson AM, Rohfs EM, Silverman LM. Proteins. In: Burtis CA, Ashwood ER. Editors Tietz text book for clinical chemistry. 3rd edition. W.B Saunders Company Philadelphia; 477-540.

24. Rajasekaran A, Kalaivani M. Antioxidant activity of aqueous extract of Monascus fermented Indian variety of rice in high cholesterol diet fedStreptozotocin diabetic rats, an in vivo study. Int $\mathbf{J}$ Cur Sci Res. 2011;1(2): 35-8.

25. Ray S. Evaluation of Protective Role of Ascorbic Acid on Flutamide-Induced Lipid Peroxidation. Int J Pharm Tech Res. 2012;4(1): 135-40.

26. Saivasanthi V, Swathi K, Aakruthi, Rani S, Gupta A, Rao AS et al. Evaluation of Carallum Fimbrita for Analgesic, Anti-inflammatory and Anxiolytic Activities. Int J Pharm. 2011;1(1): 40-5.

27. Oyedemi SO, Brandley G, Alfolayan J. In vitro and vivo antioxidant activities of aqueous extract of Strychnos henningsii Gilg. African J pharm Pharmacol. 2010;4(2): 70-8.

28. Carolina M, Casellini, Aaron IV. Recent advances in the treatment of diabetic neuropathy. Curr opin Endocrinol Diabetes. 2006;13:147-53.

29. Tesfaye S, Stevens LK, Stephenson JM, et al. Prevalence of diabetic peripheral neuropathy and its relation to glycaemic control and potential risk factors: the EURODIAB IDDM Complications Study. Diabetologia. 1996;39(11):1377-84

30. Enkhmaa B, Ozturk Z, Anuurad E, Berglund L. Postprandial Lipoproteins and Cardiovascular Disease Risk in Diabetes Mellitus. Current Diabetes Reports. 2010;10(1):61-69.

31. Sankaranarayanan C, Pari L. Thymoquinone ameliorates chemical induced oxidative stress and $\beta$ cell damage in experimental hyperglycemic rats. Chem Biol Interact 2011;190(2):148-54. 